\title{
CORRELAÇÃO DA TEMPERATURA NA PARTE SUL DO OCEANO ATLÂNTICO COM O NDC* EM MATO GROSSO
}

\author{
NAYHARA DE Lima OLIVEIRA ${ }^{1}$ \\ Instituto Federal de Goiás \\ Francisco FERnANdo Noronha MARCUZZO² \\ Companhia de Pesquisa de Recursos Minerais
}

\begin{abstract}
Resumo: Um melhor detalhamento do comportamento da precipitação pluvial, com vistas ao seu entendimento e aproveitamento máximo nas atividades humanas, pode ser obtido através do estudo do Número de Dias de Chuva (NDC) e da sua correlação com fenômenos climáticos. O presente trabalho teve como objetivo relacionar a variação do NDC no estado do Mato Grosso com a intensidade das variações de Temperatura da Superfície do Mar (TSM) do Oceano Atlântico Sul. Utilizaram-se informações de 76 estações pluviométricas com 30 anos de dados e de 44 estações com referências de 20 a 29 anos, sendo que toda a série histórica encontra-se entre os anos de 1982 a 2006. Os dados mensais de intensidade das variações TSM do Oceano Atlântico Sul foram obtidos por meio do Serviço Climatológico Nacional dos Estados Unidos, os quais foram relacionados aos dados mensais do NDC. No período de 1982 a 2006 a variação TSM mensal média foi entre $-0,7^{\circ} \mathrm{C}$ e $0,3^{\circ} \mathrm{C}$, sendo a maior variação TSM negativa de $-1,0^{\circ} \mathrm{C}$ e a maior variação TSM positiva de $0,8^{\circ} \mathrm{C}$. No geral, o NDC de cada ano cresceu e diminuiu proporcionalmente tanto nos episódios de variação TSM negativa quanto nos episódios de variação TSM positiva, não permitindo, assim, que se delimitasse qual das variações TSM mais influencia no NDC. Dessa maneira, conclui-se que as variações TSM não causam efeitos evidentes no NDC do estado de Mato Grosso.

Palavras-chave: Temperatura da Superfície do Mar; Número de Dias de Chuva; Oceano Atlântico.
\end{abstract}

\section{CORRELATION OF TEMPERATURE ON THE SOUTH ATLANTIC OCEAN TO THE NDR ON MATO GROSSO}

Abstract: A more detailed behavior of rainfall, with a view to their understanding and use in most human activities, can be obtained from the study of the Number of Days of Rain (NDC) and its correlation with climatic phenomena. This study aimed to correlate the variation in the Number of Days of Rain of Mato Grosso State with the intensity variations of Sea Surface Temperature (SST) in

\footnotetext{
* Número de Dias de Chuva.

${ }^{1}$ Instituto Federal de Goiás. Contato: nayhara_lo@hotmail.com.

2 Companhia de Pesquisa de Recursos Minerais - Serviço Geológico do Brasil. Contato: francisco.marcuzzo@cprm.gov.br.
} 
the South Atlantic Ocean. We used data from 76 rainfall stations with 30 years of data and 44 stations ranging from 20 to 29 years, and throughout this series between the years 1982 to 2006 . The monthly data of intensity variations of the SST of South Atlantic were obtained from the Climatological National Service of the United States (NOAA), which were related to the monthly NDC. In the period 1982 to 2006 the average monthly SST variation ranged from $-0,7^{\circ} \mathrm{C}$ and $0,3^{\circ} \mathrm{C}$, the largest negative SST variation was $-1.0^{\circ} \mathrm{C}$ and the largest positive SST variation was $0.8^{\circ} \mathrm{C}$. Overall the NDC each year increased and decreased proportionally in both episodes of negative SST variations and SST variation in episodes of positive, thereby not define which of the more influence SST variations in the NDC. Thus it is concluded that the SST variations cause no obvious effects on the number of rainy days in the State of Mato Grosso.

Keywords: Sea Surface Temperature; Number of Days of Rain; Atlantic Ocean.

\section{Introdução}

Estudos das variações de temperatura nas águas do Oceano Atlântico comprovam a influência dos fenômenos oceânicos sob o ciclo hidrológico e salientam a importância de estudos sobre o comportamento pluviométrico, que é uma das essências para o manejo dos recursos naturais e, consequentemente, da boa condução das atividades humanas. Devido à grande dificuldade de consistência de dados, grande espaçamento físico entre as localizações das estações pluviométricas, pequeno espaçamento temporal de dados pluviométricos - notadamente escassos no estado de Mato Grosso - há uma carência muito acentuada de estudos que mostrem a correlação entre as chuvas neste estado e as anomalias de temperatura da superfície do Oceano Atlântico.

Desde a antiguidade o homem sofre com desastres climáticos e suas variabilidades, que causam por vezes secas ou inundações catastróficas. Contudo, com a evolução da ciência meteorológica notadamente a partir dos anos 1980, várias são as pesquisas que buscam desvendar o porquê dessas irregularidades. Nessa busca constante verificou-se que a temperatura da superfície do mar tem forte influência no tempo de cada região (SOUSA et al., 2008).

Marcuzzo et al. (2011a), em um estudo sobre o comportamento temporal da chuva no bioma amazônico de Mato Grosso, verificaram que os meses que sofreram decréscimos em sua precipitação pluviométrica foram: janeiro, fevereiro, abril, maio, junho, agosto, setembro, outubro, novembro e dezembro. Ficando os meses de março e julho com crescimento da precipitação pluviométrica. Utilizando-se uma análise de regressão matemática linear, os autores observaram uma tendência de diminuição nos índices pluviométricos médios entre 1977 e 2006, para o estado de Mato Grosso, na ordem de $-12,25 \%$.

Os maiores índices pluviais no bioma do Cerrado do estado de Mato Grosso concentraram-se nas estações da primavera e verão, ou seja, de outubro a março, correspondendo a 87,5\% do volume precipitado na média histórica de 1977 a 2006. Já abril e setembro são meses que antecedem a mudança do comportamento hídrico em Mato Grosso (MARCUZZO et al., 2011c). Na Mata Atlântica Sul-MatoGrossense, Mello et al. (2011) verificaram que choveu mais na parte sul durante o período analisado. Os autores relataram que isso ocorreu porque no extremo sul de 
Mato Grosso do Sul o clima é do tipo tropical de altitude, que no Brasil sofre maior influência da massa de ar tropical atlântica - uma massa de ar quente e úmida - o que traz muita chuva para a região.

Segundo Silva et al. (2011), foi a partir dos estudos de Walker (1928) que se iniciaram várias pesquisas em busca da compreensão mais aprofundada de como Anomalias na Temperatura da Superfície do Mar (ATSM) podem causar interferências nos padrões de circulação atmosféricas e, consequentemente, afetar o regime pluviométrico em determinadas regiões do globo terrestre. Walker (1928) observou uma relação entre as secas do Nordeste do Brasil e anomalias de temperatura das águas superficiais no Pacífico Equatorial. Liebmann e Marengo (2001) verificam que a ATSM do Atlântico Equatorial está positivamente correlacionada com a precipitação do leste da Amazônia durante o outono e a primavera.

Fischer et al. (2008) destacam que muitos pesquisadores desenvolveram trabalhos sobre previsão climatológica para o Brasil apontando a Temperatura da Superfície do Mar (TSM) como um dos principais indicadores das variações de precipitação e temperatura, sendo, portanto, um importante preceptor não só para essas variáveis. Além disso, os autores denotam a importância em adotar o Número de Dias de Chuva (NDC) ao invés da Precipitação Total Anual, já que através do NDC é possível ter uma ideia da intensidade da precipitação pluvial, pois ao se analisar o mesmo total de chuva em intervalos de tempo distintos revela-se qual a intensidade e a variabilidade quantitativa e qualitativa da mesma.

Barnston e Smith (1996), concluíram que com base no Número de Dias de Chuva (NDC) é possível obter uma ideia da intensidade da precipitação pluvial, já que a análise do total de chuva em intervalos de tempo distintos revela sua intensidade e a variabilidade quantitativa e qualitativa.

A destreza de um modelo de previsão, seja ele de tempo ou clima, está ligada à qualidade do preceptor. A TSM, nos modelos climatológicos, tem demonstrado ser um preditor eficiente nos prognósticos de precipitação pluvial (MARQUES, 2005).

$\mathrm{Na}$ análise das chuvas do estado de Mato Grosso, Marcuzzo et al. (2011b) verificaram que os maiores índices pluviais concentraram-se na estação do ano primavera-verão, de outubro a março, correspondendo a cerca de $86,5 \%$ do volume precipitado para a média histórica de 1977 a 2006. Os menores índices de chuvas ocorreram no inverno, de julho a agosto, correspondendo a 13,5\%. Já abril e setembro são meses que antecedem a mudança do comportamento hídrico em Mato Grosso.

Diante da escassez de pesquisas sobre a influência da variação da temperatura da parte sul do Oceano Atlântico na região Centro-Oeste do Brasil, bem como de suas consequências no âmbito da distribuição temporal das chuvas, o objetivo deste estudo é analisar o impacto da variação na temperatura da parte sul do Oceano Atlântico no Número de Dias de Chuva no Estado de Mato Grosso, a partir do estudo da sua dispersão, correlação, medidas de tendência central e de variação dos valores. 


\section{Material e Métodos}

O Estado de Mato Grosso (Figura 1) está localizado na região Centro-Oeste do Brasil. Ele possui uma área total de $903.329,700 \mathrm{~km}^{2}$ e um perímetro de $5.815,15$ $\mathrm{km}$, divididos entre 141 municípios; sendo o maior território o do município de Aripuanã (com uma área de $65.639,97 \mathrm{~km}^{2}$ e perímetro de $1.288,36 \mathrm{~km}$ ) e o menor, o do município de São Pedro da Cipa (área de $343,89 \mathrm{~km}^{2}$ e perímetro de 108,82 $\mathrm{km})$. Segundo dados do IBGE (2010), toda a população residente nos municípios do estado de Mato Grosso soma 3.035.122 pessoas, sendo que a maior densidade populacional pertence ao município de Cuiabá, com 163,88 habitantes $/ \mathrm{km}^{2}$.


Figura 1: Densidade de habitantes por quilômetro quadrado, clima e localização do estado de Mato Grosso.

O clima do estado, segundo a classificação de Köppen é em grande parte o Tropical $(A w)$, com estação seca no inverno (conforme Figura 1); ficando uma pequena parte ao norte do estado com o clima Tropical Monçônico ( $A m)$, com chuvas excessivas durante o ano, porém o inverno seco (PEEL et al., 2007).

No presente trabalho foram utilizados dados do projeto SRTM (Shuttle Radar Topographic Mission), por meio do qual obteveram-se imagens com resolução de 90 metros, as quais foram agrupadas em um programa GIS (Geographic Information System) e em seguida o MDE (Modelo Digital de Elevação) foi delimitado, o que permitiu analisar a hipsometria do estado de Mato Grosso. 
O Mato Grosso está inserido nos biomas Amazônia, Cerrado e Pantanal (Figura 2). Segundo os dados extraídos por SRTM, a amplitude altimétrica do estado varia de 44 a 1.155 metros, sendo que as regiões sudoeste e sudeste do apresentam as maiores altitudes.

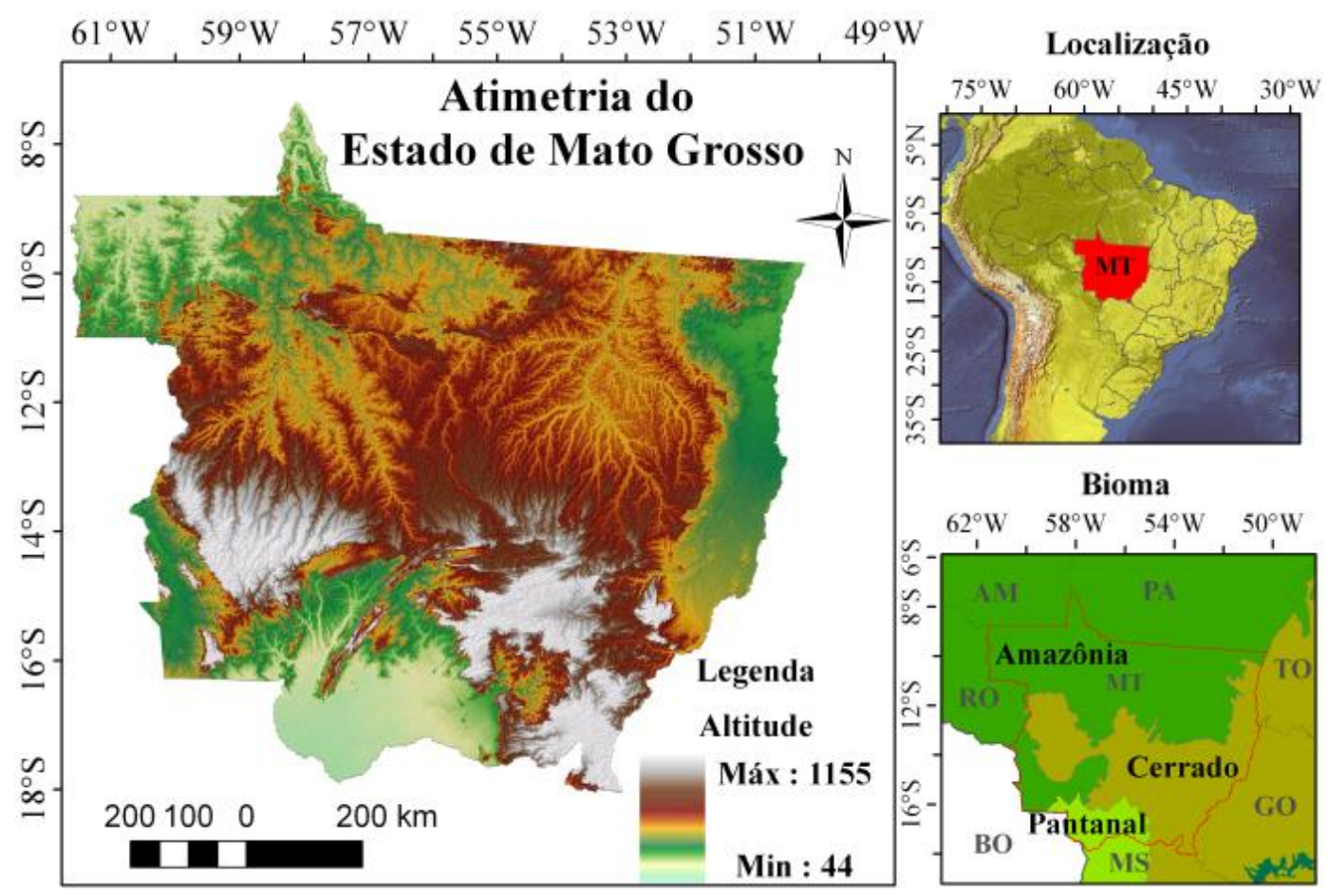

Figura 2: Relevo, altimetria, localização e bioma do estado de Mato Grosso.

O uso do solo no estado de Mato Grosso se distribui entre a pecuária, a agricultura e a agropecuária, porém a maior parte é ocupada por vegetação remanescente (Figura 3).

Utilizou-se neste estudo 120 estações pluviométricas (Figura 3), sendo 76 estações pluviométricas com 30 anos de dados e 44 estações com a coleta variando entre 20 e 29 anos e os dados mensais do Número de Dias de Chuva utilizados aqui foram obtidos através da Rede Hidrometeorológica Nacional da Agência Nacional de Águas (ANA) e da Companhia de Pesquisa de Recursos Minerais / Serviço Geológico do Brasil (CPRM/SGB). Os dados diários de NDC correspondem a uma série histórica de 1982 a 2006 e foram compilados, consistidos, organizados e tratados estatisticamente, com informação diária, mensal, anual e sazonal. Tais dados também foram trabalhados por Pinto et al. (2011) e utilizados por Oliveira e Marcuzzo (2013). 




Figura 3: Uso e ocupação do solo, estações pluviométricas e localização do estado do Mato Grosso.

A Temperatura da Superfície do Mar (TSM) é um índice que identifica as anomalias da superfície do oceano através de média móvel de três meses. Quando a variação TSM for maior que $0,0^{\circ} \mathrm{C}$ por no mínimo cinco meses consecutivos ela é denominada positiva, e quando a variação TSM for menor que $0,0^{\circ} \mathrm{C}$ por no mínimo cinco meses consecutivos, é denominada negativa. Assim, variações TSM neste estudo referem-se à diferença entre o valor momentâneo da temperatura das águas do Oceano Atlântico Sul e a temperatura considerada normal para aquele período. No Quadro 1 observa-se a intensidade da variação TSM no Oceano Atlântico Sul (0$20^{\circ} \mathrm{Sul}, 30^{\circ}$ Oeste, $10^{\circ}$ Leste), dados obtidos do Serviço Climatológico Nacional dos Estados Unidos (NOAA - National Weather Service). 
Variação TSM no Oceano Atlântico Sul

Ano

DJF JFM FMA MAM AMJ MJJ JJA JAS ASO SON OND NDJ

Média

\begin{tabular}{|c|c|c|c|c|c|c|c|c|c|c|c|c|c|}
\hline 1982 & $-0,18$ & $-0,31$ & $-0,33$ & $-0,55$ & $-0,63$ & $-0,48$ & $-0,51$ & $-0,81$ & $-0,51$ & $-0,33$ & $-0,42$ & 0,34 & $-0,39$ \\
\hline 1983 & 0,09 & 0,09 & $-0,29$ & $-0,43$ & $-0,65$ & $-0,66$ & $-0,53$ & $-0,30$ & $-0,20$ & $-0,37$ & $-0,11$ & 0,15 & $-0,27$ \\
\hline 1984 & 0,37 & 0,41 & 0,40 & 0,22 & 0,10 & 0,34 & 0,30 & 0,59 & 0,62 & 0,38 & 0,20 & 0,16 & 0,34 \\
\hline 1985 & 0,21 & 0,25 & $-0,07$ & $-0,11$ & $-0,07$ & $-0,14$ & 0,02 & 0,07 & $-0,04$ & 0,09 & 0,13 & 0,01 & 0,03 \\
\hline 1986 & $-0,07$ & 0,18 & 0,09 & 0,01 & 0,09 & 0,19 & 0,05 & 0,13 & 0,14 & $-0,02$ & $-0,18$ & $-0,11$ & 0,04 \\
\hline 1987 & $-0,17$ & $-0,15$ & $-0,16$ & $-0,06$ & 0,09 & 0,18 & 0,24 & 0,15 & 0,13 & 0,22 & 0,46 & 0,17 & 0,09 \\
\hline 1988 & 0,49 & 0,25 & 0,42 & 0,37 & 0,49 & 0,53 & 0,41 & 0,34 & 0,12 & 0,15 & $-0,01$ & 0,07 & 0,30 \\
\hline 1989 & 0,46 & 0,16 & 0,15 & 0,14 & 0,18 & 0,15 & 0,14 & 0,33 & 0,15 & 0,12 & $-0,18$ & $-0,50$ & 0,11 \\
\hline 1990 & $-0,57$ & $-0,14$ & 0,04 & 0,11 & $-0,20$ & 0,06 & $-0,12$ & $-0,23$ & $-0,05$ & 0,07 & 0,06 & 0,11 & $-0,07$ \\
\hline 1991 & $-0,15$ & $-0,21$ & $-0,09$ & 0,07 & 0,31 & 0,10 & $-0,15$ & $-0,20$ & $-0,38$ & $-0,38$ & $-0,54$ & $-0,17$ & $-0,15$ \\
\hline 1992 & $-0,28$ & $-0,41$ & $-0,74$ & $-0,88$ & $-0,96$ & $-1,04$ & $-0,81$ & $-0,77$ & $-0,67$ & $-0,77$ & $-0,82$ & $-0,69$ & $-0,74$ \\
\hline 1993 & $-0,49$ & $-0,40$ & $-0,36$ & $-0,11$ & $-0,27$ & $-0,22$ & $-0,09$ & $-0,13$ & 0,41 & 0,42 & 0,58 & 0,46 & $-0,02$ \\
\hline 1994 & 0,10 & $-0,12$ & 0,06 & 0,14 & 0,08 & $-0,23$ & $-0,45$ & $-0,20$ & $-0,28$ & $-0,26$ & 0,03 & $-0,10$ & $-0,10$ \\
\hline 1995 & 0,01 & 0,28 & 0,50 & 0,53 & 0,38 & 0,39 & 0,16 & $-0,13$ & $-0,17$ & $-0,21$ & $-0,16$ & $-0,21$ & 0,11 \\
\hline 1996 & $-0,03$ & 0,26 & 0,16 & 0,41 & 0,48 & 0,53 & 0,45 & 0,30 & 0,10 & $-0,07$ & $-0,21$ & $-0,44$ & 0,16 \\
\hline 1997 & $-0,08$ & $-0,82$ & $-0,87$ & $-0,99$ & $-0,98$ & $-0,92$ & $-0,60$ & $-0,40$ & $-0,13$ & 0,37 & 0,67 & 0,82 & $-0,33$ \\
\hline 1998 & 0,73 & 0,43 & 0,27 & 0,27 & 0,28 & 0,36 & 0,49 & 0,13 & 0,12 & $-0,02$ & 0,14 & $-0,16$ & 0,25 \\
\hline 1999 & $-0,35$ & $-0,27$ & $-0,13$ & 0,21 & 0,23 & 0,17 & 0,42 & 0,24 & 0,04 & 0,07 & 0,03 & 0,19 & 0,07 \\
\hline 2000 & $-0,01$ & 0,14 & $-0,05$ & 0,04 & 0,07 & 0,02 & $-0,07$ & 0,10 & $-0,01$ & 0,00 & $-0,08$ & $-0,28$ & $-0,01$ \\
\hline 2001 & $-0,19$ & $-0,29$ & $-0,15$ & 0,01 & 0,27 & 0,13 & $-0,08$ & $-0,08$ & $-0,19$ & $-0,06$ & $-0,10$ & $-0,34$ & $-0,09$ \\
\hline 2002 & $-0,35$ & $-0,48$ & $-0,18$ & 0,09 & 0,22 & $-0,02$ & $-0,13$ & $-0,21$ & $-0,26$ & $-0,12$ & $-0,37$ & $-0,06$ & $-0,16$ \\
\hline 2003 & 0,15 & 0,32 & 0,36 & 0,15 & 0,01 & $-0,09$ & 0,31 & 0,49 & 0,38 & 0,37 & 0,42 & 0,42 & 0,27 \\
\hline 2004 & 0,20 & $-0,13$ & $-0,41$ & $-0,62$ & $-0,48$ & $-0,36$ & $-0,09$ & 0,08 & 0,18 & $-0,18$ & $-0,07$ & 0,17 & $-0,14$ \\
\hline 2005 & 0,44 & 0,45 & 0,29 & $-0,09$ & $-0,35$ & $-0,53$ & $-0,32$ & $-0,11$ & $-0,09$ & $-0,04$ & $-0,09$ & $-0,15$ & $-0,05$ \\
\hline 2006 & $-0,22$ & 0,10 & 0,25 & 0,16 & 0,22 & 0,38 & 0,33 & 0,23 & 0,18 & 0,07 & 0,03 & 0,10 & 0,15 \\
\hline
\end{tabular}




\section{Regressão linear e polinomial}

São métodos para estimar a condicional de uma variável $Y$, dados os valores de algumas outras variáveis $X$. A regressão, em geral, trata da questão de estimar um valor condicional esperado. Em muitas situações uma relação linear pode ser válida para sumarizar a associação entre as variáveis $Y$ e $X$. Já a regressão polinomial, tende a descrever o caminhamento da evolução da variável dependente $Y$ conforme as modificações da variável $X$. A regressão linear e polinomial são, respectivamente, descritas como:

$$
\begin{aligned}
& Y=\beta_{0}+\beta_{1} X \\
& Y=\beta_{6} X^{6}+\beta_{5} X^{5}+\cdots+\beta_{1} X+\beta_{0}
\end{aligned}
$$

Onde, $Y$ é a variável linear dependente; $\beta_{6}, \beta_{5}, \ldots, \beta_{1}$, e $\beta_{0}$ são os coeficientes da regressão e $X$ é a variável independente.

\section{Verificação estatística descritiva}

Através da estatística descritiva podemos ter características essenciais à formação de histograma de frequências relativas de uma amostra de dados hidrológicos (NAGHETTINI \& PINTO, 2007). Para este estudo foram calculadas as seguintes medidas de tendência central e de dispersão.

\section{- Medidas de tendência central}

É a medida de posição mais frequentemente usada e tem um significado teórico importante na estimativa de amostras. É calculada pela seguinte fórmula:

$$
\mathrm{X}=\frac{\mathrm{X}_{1}, \ldots, \mathrm{X}_{\mathrm{n}}}{\mathrm{N}}=\frac{1}{\mathrm{~N}} \sum_{\mathrm{i}=1}^{\mathrm{N}} \mathrm{X}_{1}
$$

Onde, $X$ é a média; $N$ é o tamanho da amostra; $X_{1}$ até $X_{n}$ são os somatórios da amostra.

A mediana é outra medida de posição mais resistente do que a média, por ser imune à eventual presença de valores extremos discordantes na amostra. É calculada pela seguinte equação:

$X_{\text {med }}=\frac{X_{\left(\frac{N}{2}\right)}+X_{\left(\frac{N}{2}+1\right)}}{2}$ 


\section{- Medidas de dispersão}

O desvio padrão é fortemente influenciado pelos menores e maiores desvios, constituindo-se na medida de dispersão mais frequentemente usada. É calculado pela seguinte expressão:

$\mathrm{S}=\sqrt{\frac{1}{\mathrm{~N}-1} \sum_{\mathrm{I}=1}^{\mathrm{N}}\left(\mathrm{X}_{1}-\mathrm{X}\right)^{2}}$

Onde, $N$ é o tamanho da amostra; $X_{i}$ é o valor de cada amostra; $\bar{X}$ é a média.

Utilizando-se as medidas de tendência central e de dispersão é possível verificar analiticamente os parâmetros e observar se as amostras são diferentes ou semelhantes.

\section{Resultados e Discussão}

Observa-se para o mês de janeiro (ver Figura 4) um decréscimo do NDC tanto durante os episódios de variação TSM negativa do Oceano Atlântico Sul quanto naqueles de variação positiva de TSM. A variação TSM negativa mais intensa para os meses de janeiro entre os anos de 1982 e 2006 foi de $-0,6^{\circ} \mathrm{C}$ (1990), ocasionando 16 dias de chuva; enquanto a mais intensa variação TSM positiva foi de $0,7^{\circ} \mathrm{C}$ (1998) e ocasionou 15 dias de chuva. O maior NDC observado foi de 22 dias (1985), para um valor de variação TSM de $0,2^{\circ} \mathrm{C}$. O menor NDC (11 dias) ocorreu no ano de 1993 durante um episódio de variação TSM negativa, o segundo mais forte do mês $\left(-0,5^{\circ} \mathrm{C}\right)$. 


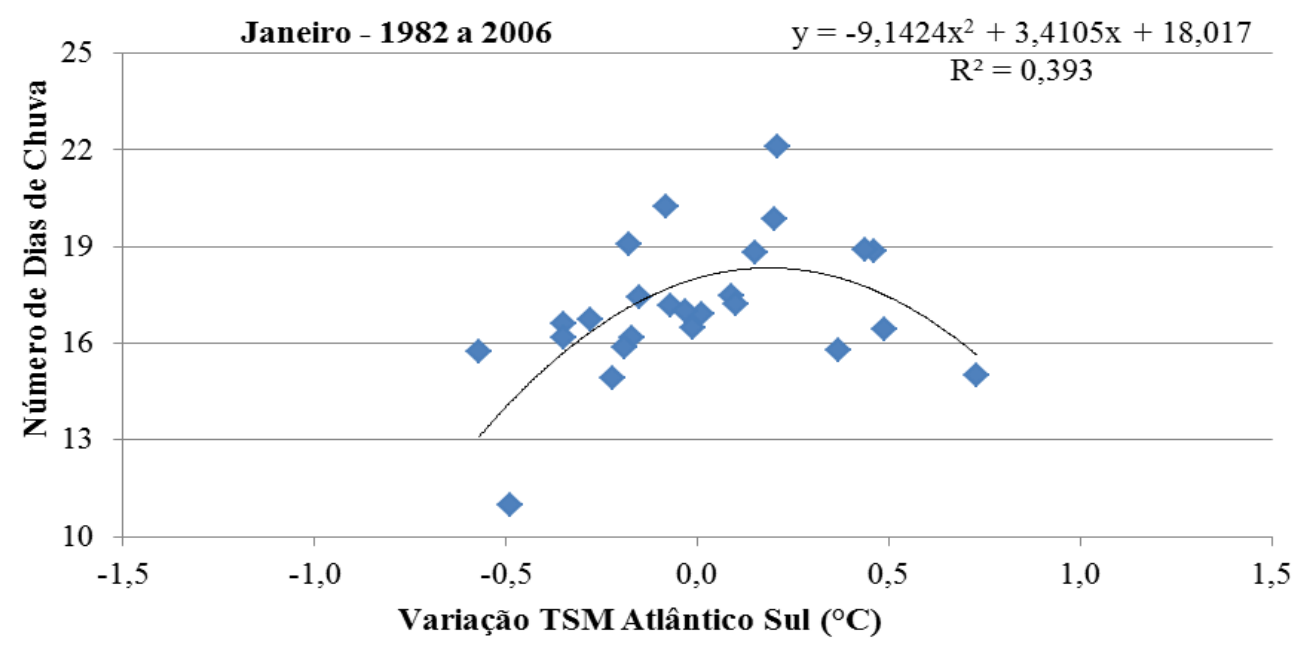

Figura 4: Dispersão em janeiro do Número de Dias de Chuva em relação à variação TSM do Atlântico Sul no período.

No mês de fevereiro (Figura 5) constata-se um decréscimo pouco significativo do NDC, tanto na ocorrência de variações TSM positiva quanto nas variações TSM negativa. O mês de fevereiro do ano de 2005 esteve sob influência da maior variação TSM positiva para este mês $\left(0,5^{\circ} \mathrm{C}\right)$ e apresentou o menor NDC da série histórica para janeiro (12 dias). Contudo, o maior NDC (18 dias) aconteceu sob influência da segunda menor variação TSM negativa $\left(-0,1^{\circ} \mathrm{C}\right)$, no ano de 2004 . Na maior variação TSM negativa $\left(-0,8^{\circ} \mathrm{C}\right)$ registrou-se 15 dias de chuva (1997).

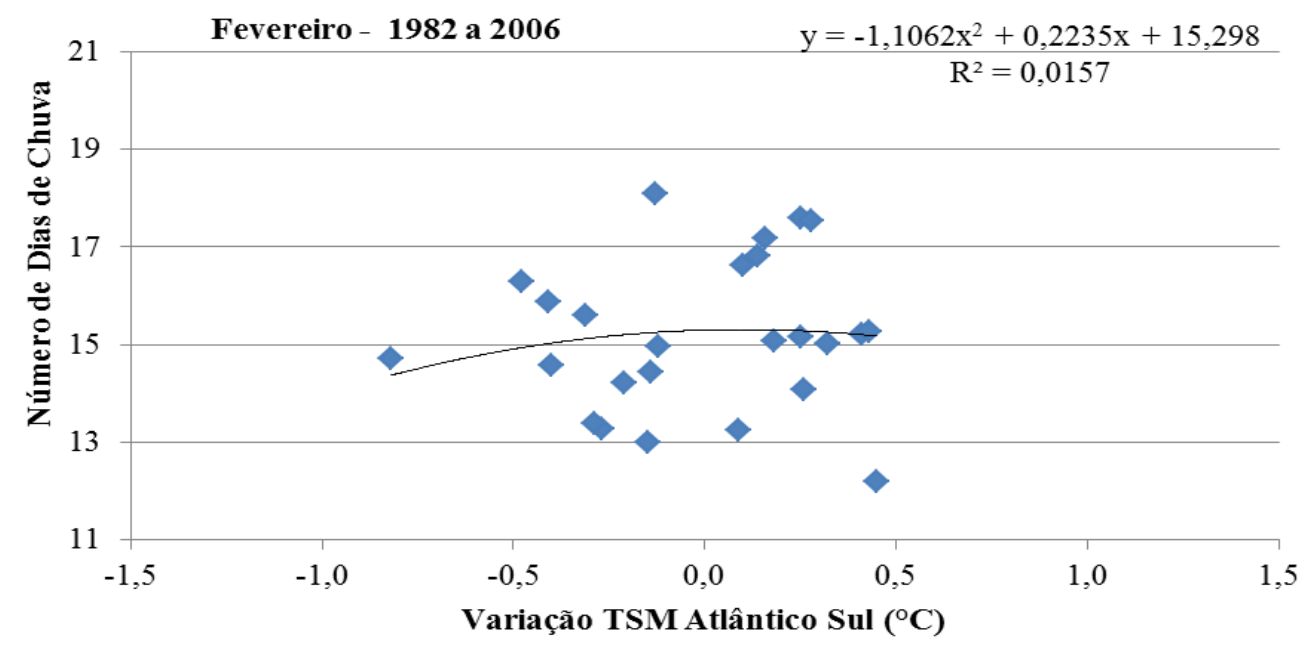

Figura 5: Dispersão em fevereiro do Número de Dias de Chuva em relação à variação TSM do Atlântico Sul no período. 
Para o mês de março (Figura 6) observa-se um acréscimo pouco considerável do NDC na ocorrência das variações TSM do Atlântico Sul, com destaque para a variação positiva. As variações TSM variaram entre $-0,9^{\circ} \mathrm{C}$ e $0,5^{\circ} \mathrm{C}$. A maior variação TSM negativa provocou um total de 17 dias de chuva (1997), enquanto a maior variação TSM positiva provocou um total de 13 dias de chuva (1995). O ano de 1993 apresentou o mês de março com o menor NDC (10 dias) da série histórica, período no qual a variação TSM foi de $-0,4^{\circ} \mathrm{C}$. O maior NDC para esse mês foi de 18 dias nos anos de 1988 e 2003, ambos sob variação positiva de $0,4^{\circ} \mathrm{C}$.



Figura 6: Dispersão em março do Número de Dias de Chuva em relação à variação TSM do Atlântico Sul no período.

No mês de abril (ver Figura 7) houve um acréscimo significativo do NDC. Mais da metade dos meses de abril da série histórica esteve sob influência de variações TSM positiva, contudo foi nesse mês que aconteceu um dos maiores resfriamentos das águas do Oceano Atlântico Sul $\left(-1,0^{\circ} \mathrm{C}\right)$, o que acarretou em 11 dias de chuva no ano de 1997. A maior variação TSM positiva para o mês $\left(0,5^{\circ} \mathrm{C}\right)$ aconteceu em 1995 e provocou 11 dias de chuva. O maior NDC (15 dias) e o menor NDC (6 dias) aconteceram durante episódios de variações TSM de pouca intensidade, $-0,1^{\circ} \mathrm{C}$ (1993) e $0,1^{\circ} \mathrm{C}(2002)$, respectivamente. 


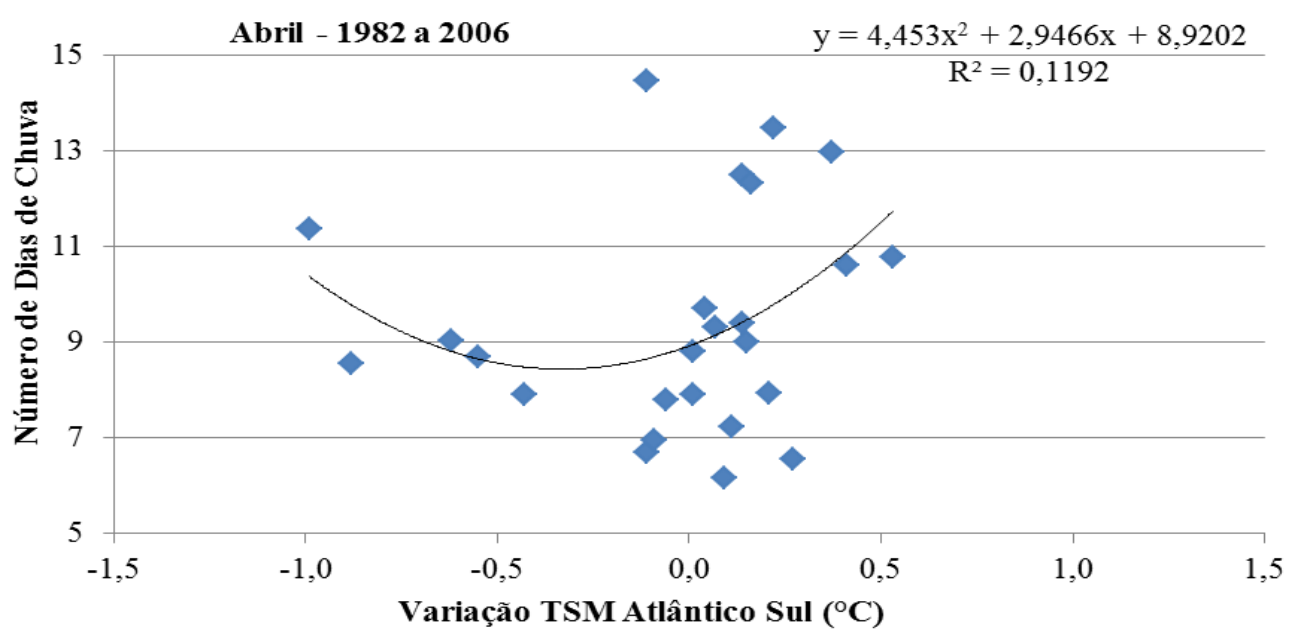

Figura 7: Dispersão em abril do Número de Dias de Chuva em relação à variação TSM do Atlântico Sul no período.

A variação TSM positiva mais intensa para o mês de maio (Figura 8) foi de $0,5^{\circ} \mathrm{C}$, caracterizando um pequeno aumento do NDC durante sua ocorrência. Tanto o maior NDC (6 dias) quanto o menor NDC (2 dias) foram observados durante a ocorrência de variações TSM positivas de baixa intensidade nos anos de 1995 e 2000 , respectivamente. A variação TSM negativa mais intensa foi de $-1,0^{\circ} \mathrm{C}$, a qual ocasionou 3 dias de chuva no ano de 1992 e 4 dias de chuva no ano de 1997. Assim, constatou-se que as anomalias negativas pouco influenciaram no aumento do NDC nos meses de maio da série histórica de 1982 a 2006.



Figura 8: Dispersão em maio do Número de Dias de Chuva em relação à variação TSM do Atlântico Sul no período 
$\mathrm{Na}$ Figura 9 pode-se observar que as variações TSM nas águas do Oceano Atlântico Sul variaram de $-1,0^{\circ} \mathrm{C}$ a $0,5^{\circ} \mathrm{C}$ e pouco interferiram no NDC dos meses de junho entre os anos de 1982 e 2006. As variações TSM positivas provocaram um pequeno decréscimo no NDC, enquanto as variações TSM negativas provocaram um acréscimo quase insignificante no NDC desse mês. O mês de junho dos anos de 2000 e 2002 não registrou variação TSM das águas do Oceano Atlântico Sul, quando também não choveu no estado de Mato Grosso. O maior NDC foi de 4 dias, sob uma variação TSM de $-0,9^{\circ} \mathrm{C}$, no ano de 1997 . A mais intensa variação TSM negativa $\left(-1,0^{\circ} \mathrm{C}\right)$ causou 1 dia de chuva.



Figura 9: Dispersão em junho do Número de Dias de Chuva em relação à variação TSM do Atlântico Sul no período.

No mês de julho (ver Figura 10) as relações entre variações TSM e dias de chuva foram inversamente proporcionais; enquanto as intensidades das variações TSM aumentaram, os dias de chuva diminuíram. Como julho se caracteriza pela estiagem no estado de Mato Grosso, o maior NDC registrado para esse mês na série histórica foi 2 dias (1989) e não estava sob influência de variações TSM. Não choveu no mês de julho dos anos de 1984, 1987, 1988, 1991, 1992, 1995, 1996, 1997, 1998, 2003 e 2005 , nos quais a variação TSM variou de $-0,8^{\circ} \mathrm{C}$ a $0,5^{\circ} \mathrm{C}$, incluindo aí as mais intensas variações TSM negativa e positiva do mês de julho. 


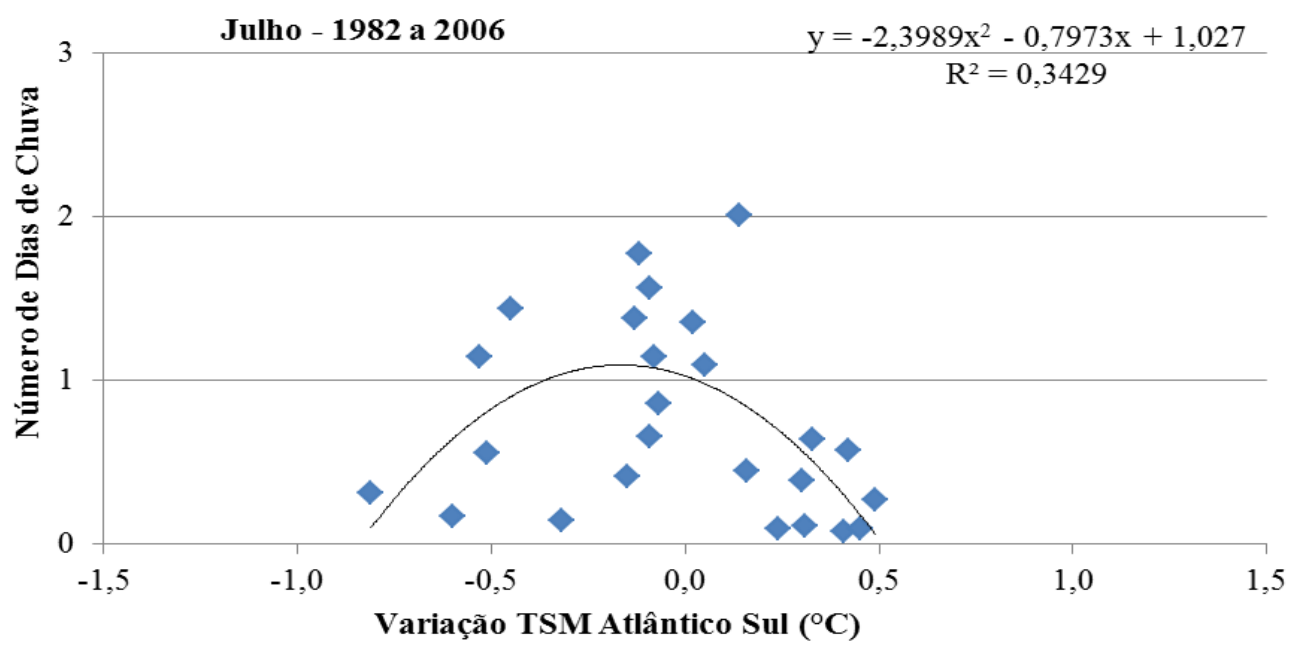

Figura 10: Dispersão em julho do Número de Dias de Chuva em relação à variação TSM do Atlântico Sul no período.

Durante o mês de agosto (Figura 11) as variações TSM aconteceram com intensidades entre $-0,8^{\circ} \mathrm{C}$ e $0,6^{\circ} \mathrm{C}$, observando-se apenas um pequeno acréscimo dos dias de chuva no estado de Mato Grosso. Na ocorrência de variações TSM mais intensas, tanto negativas quanto positivas, registrou-se 3 dias de chuva nos anos de 1982 e 1984. Em $1986\left(0,1^{\circ} \mathrm{C}\right)$ aconteceu o máximo NDC para o mês de agosto da série histórica (5 dias). Não foram registradas chuvas em agosto dos anos de 1983 ($\left.0,3^{\circ} \mathrm{C}\right), 1988\left(0,3^{\circ} \mathrm{C}\right), 1991\left(-0,2^{\circ} \mathrm{C}\right), 1999\left(0,2^{\circ} \mathrm{C}\right)$ e $2005\left(-0,1^{\circ} \mathrm{C}\right)$.

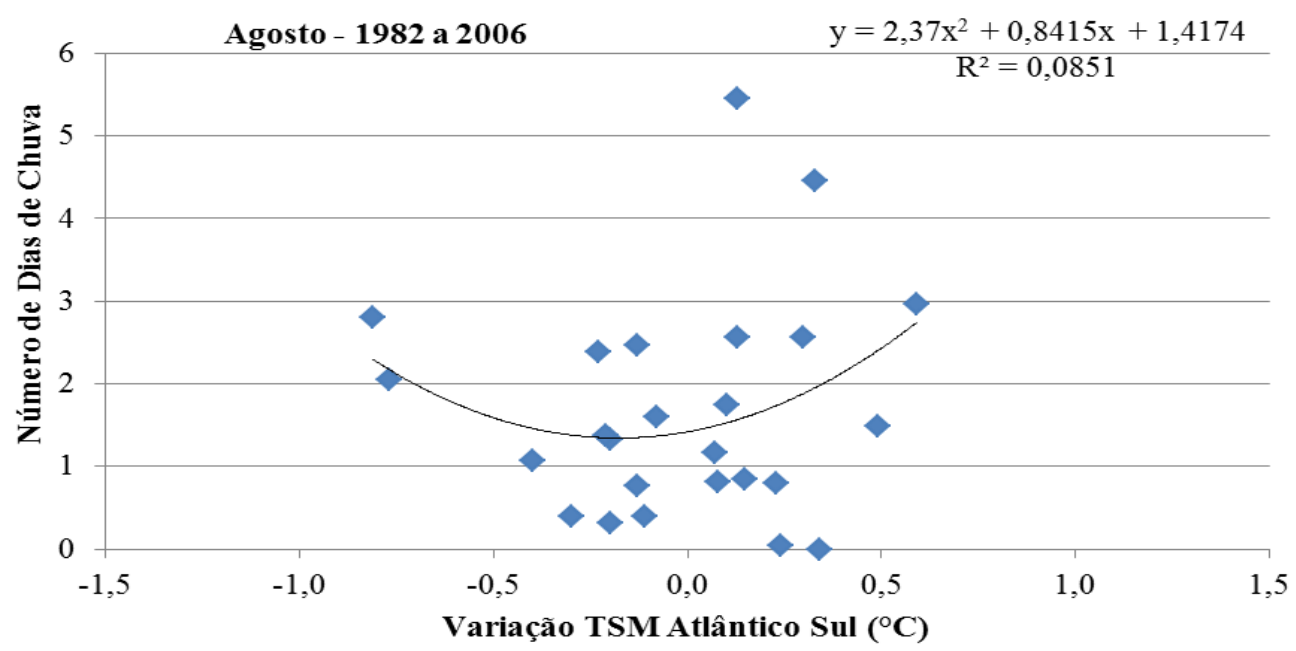

Figura 11: Dispersão em agosto do Número de Dias de Chuva em relação à variação TSM do Atlântico Sul no período. 
No mês de setembro (Figura12) aconteceu algo parecido com o que ocorreu no mês de agosto, porém o acréscimo dos dias de chuva foi maior nos períodos de variação TSM negativa. O menor NDC desse mês (2 dias) se deu durante pequenas variações TSM positivas nos anos de $1988\left(0,1^{\circ} \mathrm{C}\right)$ e $2004\left(0,2^{\circ} \mathrm{C}\right)$. Já a variação TSM negativa em sua intensidade máxima $\left(-0,7^{\circ} \mathrm{C}\right)$ ocasionou 8 dias de chuva (1992). O maior NDC (9 dias) estava sob influência de uma variação TSM de $0,5^{\circ} \mathrm{C}$, no ano de 1982 . Em 1984 registrou-se a maior variação TSM positiva $\left(0,6^{\circ} \mathrm{C}\right)$, que acarretou em 6 dias de chuva.

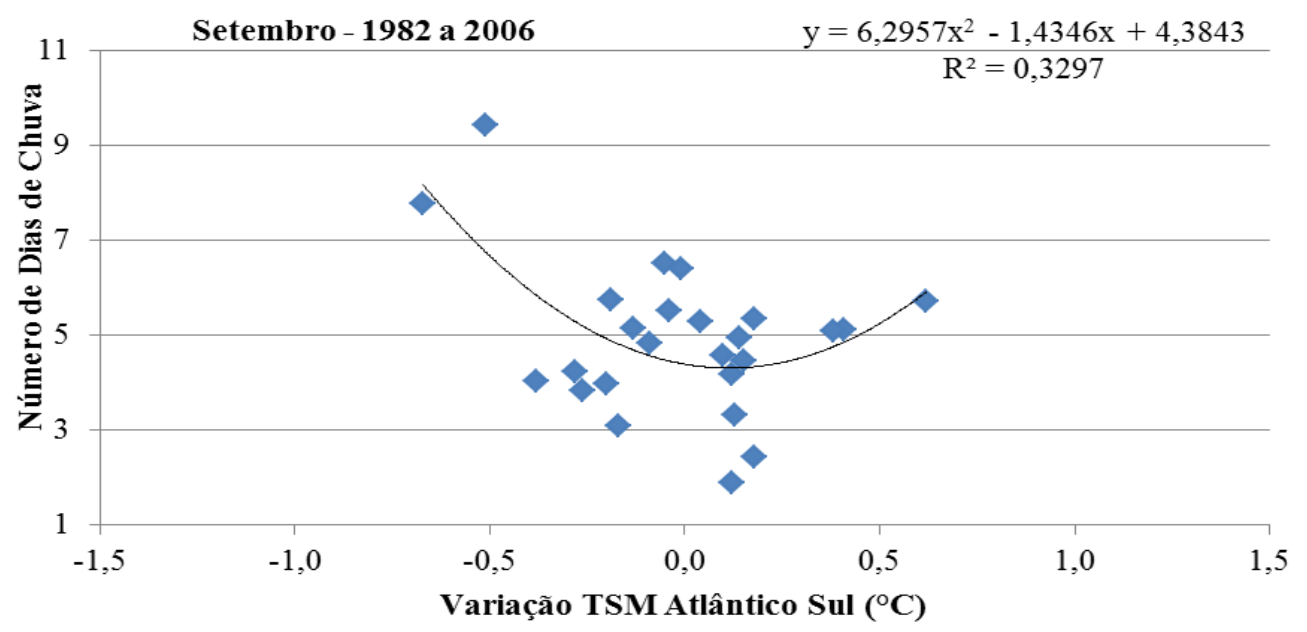

Figura 12: Dispersão em setembro do Número de Dias de Chuva em relação à variação TSM do Atlântico Sul no período.

Durante o mês de outubro (Figura 13) as variações TSM das águas do Oceano Atlântico Sul se deram entre $-0,8^{\circ} \mathrm{C}(1992)$ e $0,4^{\circ} \mathrm{C}(1984,1993$, 1997 e 2003), mas nenhuma variação da TSM interferiu consideravelmente no NDC no estado de Mato Grosso. Observou-se apenas um pequeno decréscimo durante as variações TSM negativas. No ano de $1984\left(0,4^{\circ} \mathrm{C}\right)$ se deu o outubro com maior NDC da série histórica, 13 dias. Choveu 8 dias nesse mês dos anos de 1987, 1988, 1993, 1995, 1997, 1999, 2000 e 2005, os quais estiveram sob influência de baixíssimas variações TSM, assim como na maioria dos anos. A maior variação TSM negativa provocou 9 dias de chuva no mês de outubro do ano 1992. 


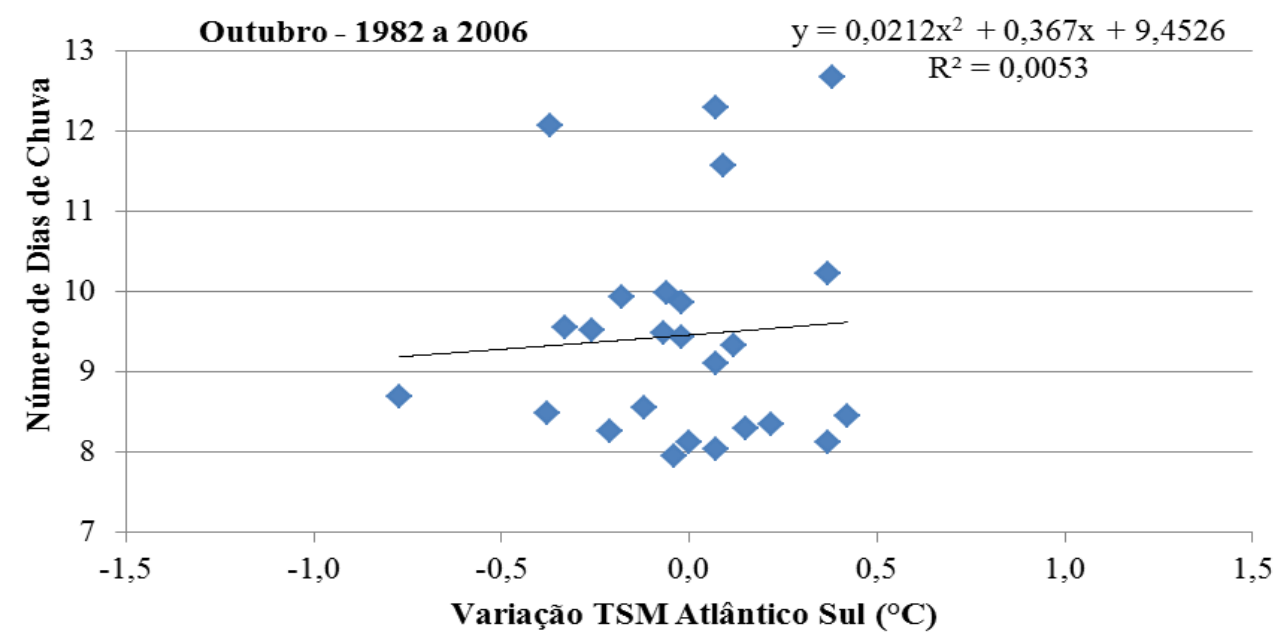

Figura 13: Dispersão em outubro do Número de Dias de Chuva em relação à variação TSM do Atlântico Sul no período.

Observando-se para o mês de novembro (Figura 14) um decréscimo do NDC na ocorrência das variações TSM tanto positivas quanto negativas. As mais intensas variações TSM negativa $\left(-0,8^{\circ} \mathrm{C}\right)$ e positiva $\left(0,7^{\circ} \mathrm{C}\right)$ durante os meses de novembro da série histórica proporcionaram 11 dias de chuva nos anos de 1992 e 1997. Esse mês em 2001 estava sob influência de uma variação negativa de $-0,1^{\circ} \mathrm{C}$ e foi o que apresentou o maior NDC (15 dias). O novembro da série histórica com menos dias de chuva foi o do ano de $1993\left(0,6^{\circ} \mathrm{C}\right)$, com 9 dias.



Figura 14: Dispersão em novembro do Número de Dias de Chuva em relação à variação TSM do Atlântico Sul no período. 
As variações TSM negativas para o mês de dezembro (Figura 15) chegaram a 0,7C (1992), observando-se durante suas ocorrências um pequeno decréscimo dos dias de chuva. Já nas ocorrências das variações TSM positivas observa-se um decréscimo maior no NDC se comparado às variações negativas, que chega a $0,8^{\circ} \mathrm{C}$ (1997). Tanto a mais intensa variação TSM negativa quanto a mais intensa variação TSM positiva provocaram 14 dias de chuva. O ano com o menor NDC (13 dias) para esse mês foi o de $1990\left(0,1^{\circ} \mathrm{C}\right)$. O maior número de dias de chuva (19 dias) foi registrado no ano de $1989\left(-0,5^{\circ}\right)$.

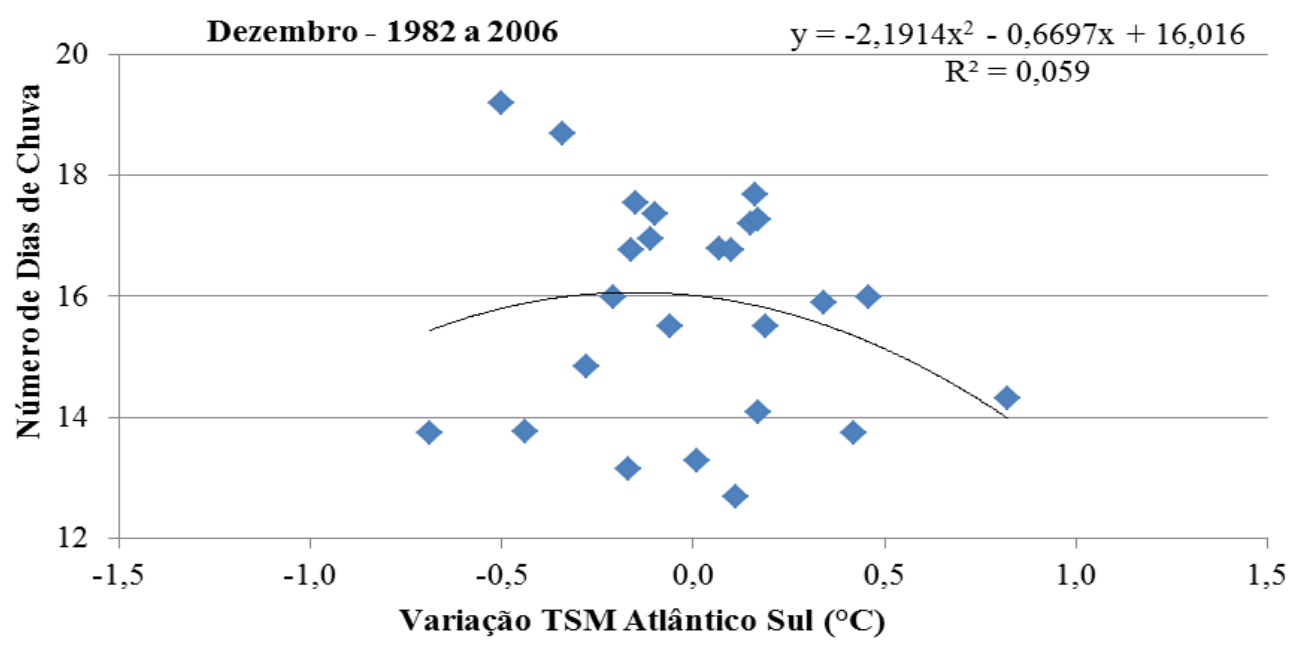

Figura 15: Dispersão em dezembro do Número de Dias de Chuva em relação à variação TSM do Atlântico Sul no período.

No período entre 1982 e 2006 (Figura 16) a Temperatura da Superfície do Mar das águas do Oceano Atlântico Sul variaram em média entre $-0,7^{\circ} \mathrm{C}$ e $0,3^{\circ} \mathrm{C}$, porém a parábola se inverteu, contrariando a maioria dos gráficos mensais - nos quais o NDC diminuía conforme aumentava a intensidade da variação TSM. Na Figura 16 o NDC do gráfico se caracteriza com a soma dos dias em que se registrou chuva de cada ano da série histórica. Observa-se que todos os anos do período estiveram sob influência de variações TSM negativas ou positivas, mesmo que sejam mínimas. No geral, o NDC de cada ano cresceu e diminuiu proporcionalmente tanto nos episódios de variações TSM negativas quanto nos episódios de variação TSM positiva, não permitindo, assim, delimitar qual das variações TSM mais influência no NDC. A maior variação TSM negativa média $\left(-0,7^{\circ}\right)$ foi registrada no ano de 1992 , no qual dos 365 dias do ano choveu em 102 dias. Já a mais forte variação TSM positiva $\left(0,3^{\circ} \mathrm{C}\right)$ foi registrada nos anos de 1984, 1988, 1998 e 2003, nos quais choveu 102, 108, 109 e 119 dias, respectivamente. $\mathrm{O}$ ano de 1993 foi o que apresentou o menor NDC do período (89 dias) e não estava sob influência de nenhuma variação TSM. Dos 365 dias do ano de 1989, choveu em 121 - o maior NDC do período -, sob a influência de uma variação TSM positiva de $0,1^{\circ} \mathrm{C}$ 


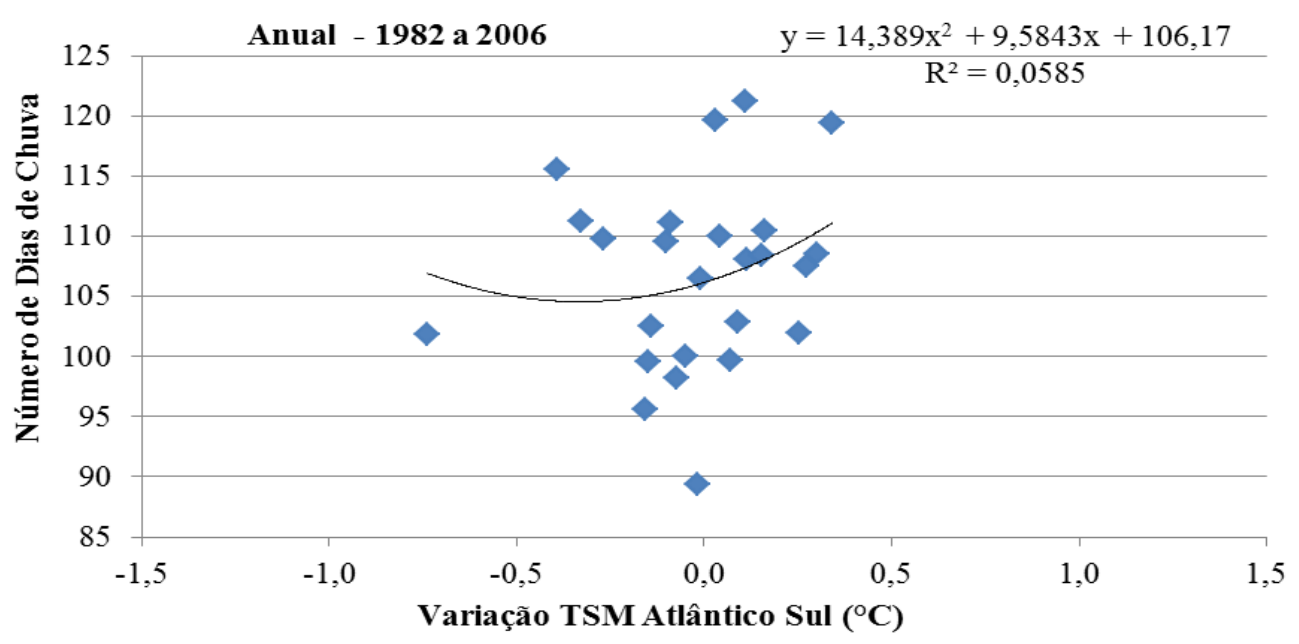

Figura 16: Dispersão anual do Número de Dias de Chuva em relação à variação TSM do Atlântico Sul no período.

De acordo com a Figura 17, dentro do período estudado (1982-2006) a variação TSM negativa com maior intensidade (variação de $-1,0^{\circ} \mathrm{C}$ na temperatura) aconteceu no ano de 1992, nos meses de maio ( 3 dias de chuva) e junho (1 dia de chuva); e no ano de 1997, nos meses de abril (11 dias de chuva) e maio (4 dias de chuva). A variação TSM positiva com maior intensidade (variação de $0,8^{\circ} \mathrm{C}$ na temperatura) ocorreu no mês de dezembro de 1997, ocasionando 14 dias de chuva. As variações positivas de temperatura são mais frequentes que as negativas, porém as variações TSM negativas acontecem com maiores intensidades que as positivas. Além disso, os maiores NDC coincidem com variações TSM negativas. 


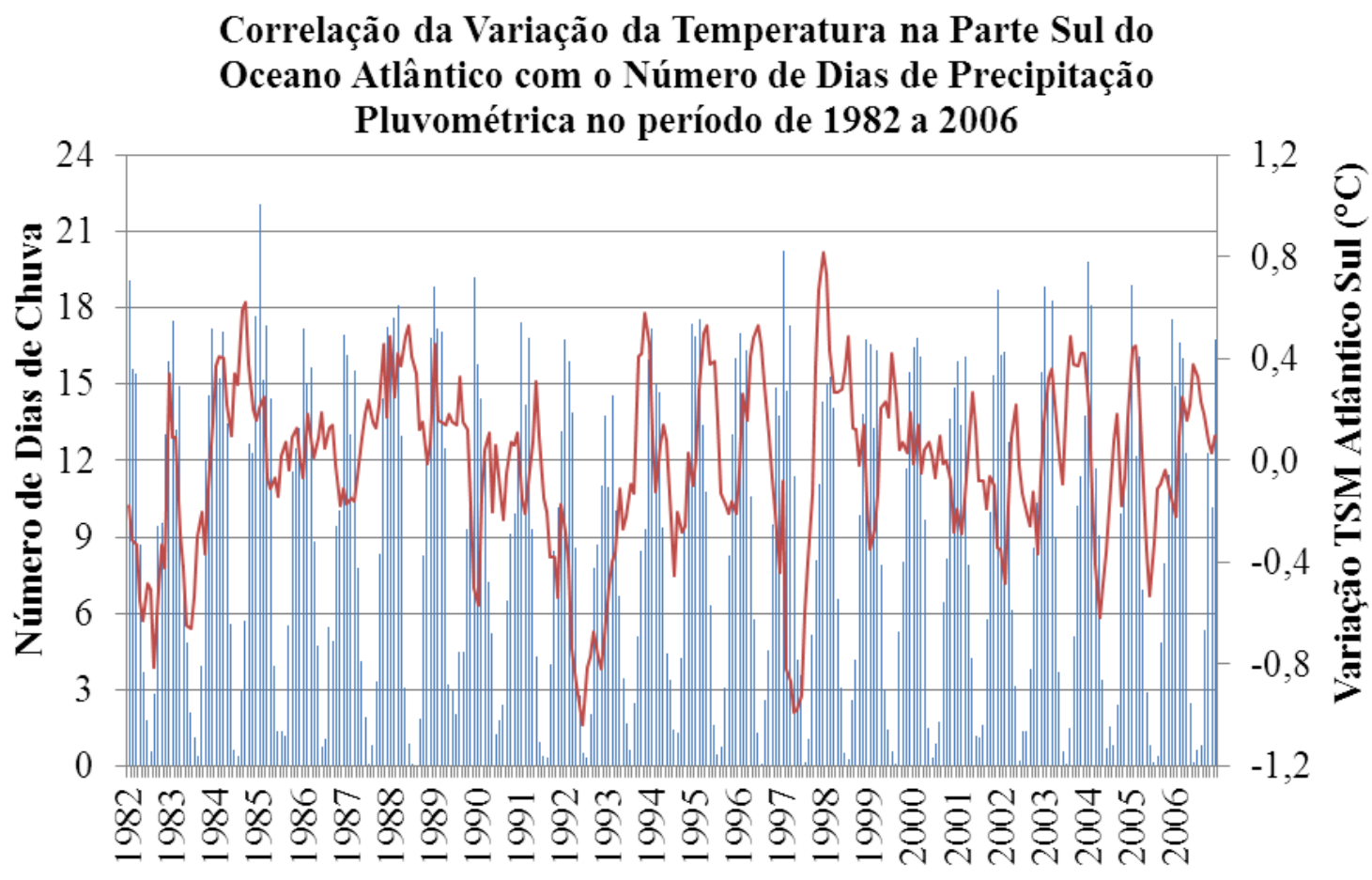

Figura 17: Influência da variação TSM do Atlântico Sul no Número de Dias de Precipitação Pluviométrica no período.

A distribuição dos valores anuais do número de dias de chuva, com base nos dados da série histórica de 1982 a 2006, apresenta uma variação pouco significativa da precipitação (ver Figura 18). A maior variação de NDC anual ocorreu no ano de 1989 (121 dias) para o ano de 1990 (98 dias). Verifica-se uma tendência de diminuição nos dias de chuva para o estado de Mato Grosso. Outros trabalhos sobre precipitação pluviométrica também foram desenvolvidos pelos autores no CentroOeste do Brasil (MARCUZZO et al., 2013; OLIVEIRA \& MARCUZZO, 2013; MARCUZZO et al., 2012; MARCUZZO \& OLIVEIRA, 2012; MARCUZZO et al., 2012; MARCUZZO \& CARDOSO, 2015), servindo como base metodológica para o desenvolvimento deste estudo. 


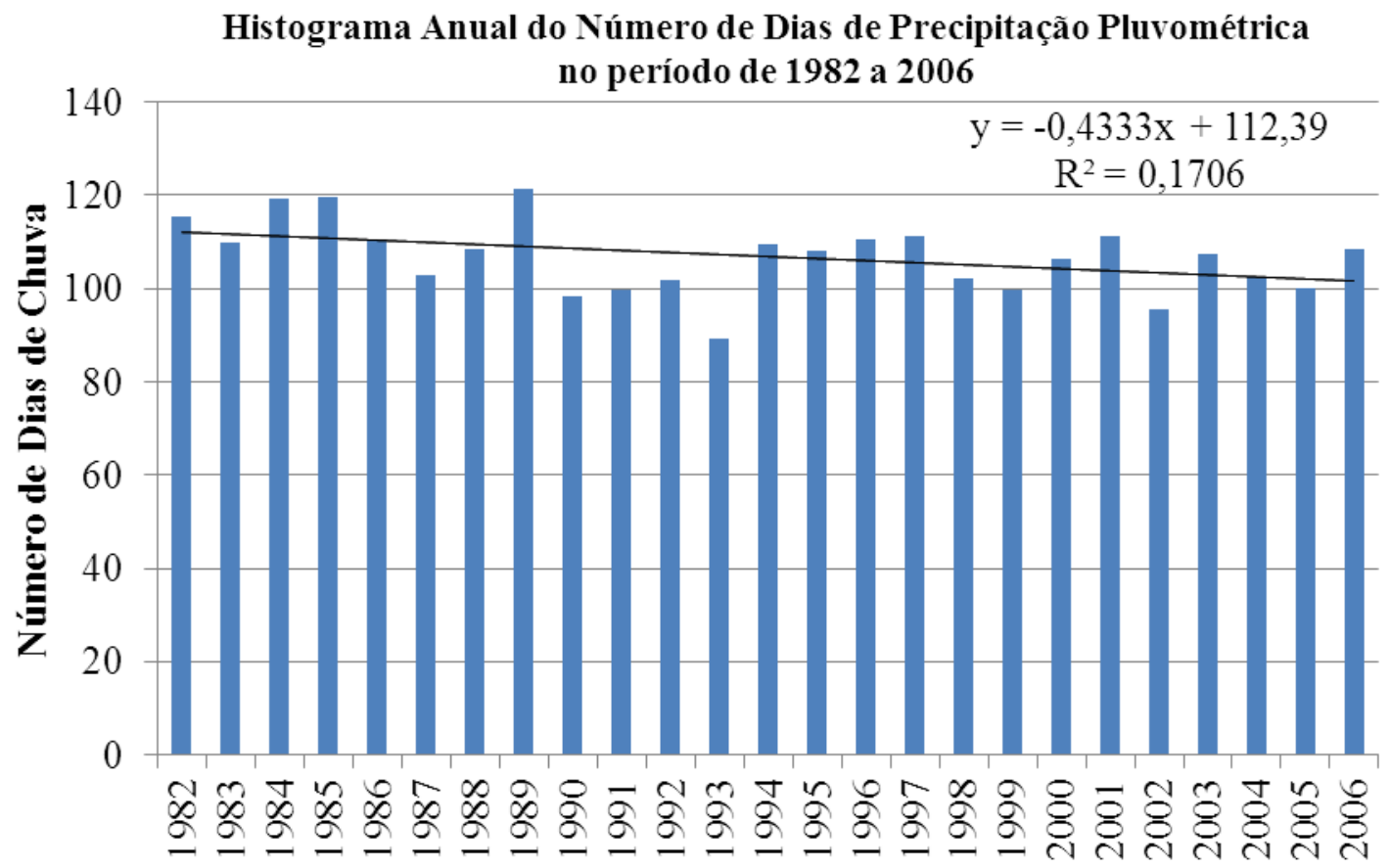

Figura 18: Distribuição temporal e análise de regressão linear do Número de Dias de Precipitação Pluviométrica, de 1982 a 2006, para o estado de Mato Grosso.

$\mathrm{Na}$ análise estatística (Tabela 1) verifica-se que o maior NDC do estado de Mato Grosso foi obtido no mês de janeiro de 1985 (aproximadamente 22 dias de chuva), quando a variação TSM estava em $0,2^{\circ} \mathrm{C}$ (Figura 4). A tendência central (média) que é o ponto médio de um grupo de números em uma distribuição estatística - para os valores de dias de chuva mostrou uma maior proximidade com os valores máximos nos meses chuvosos (de outubro a abril), em relação aos meses secos, os quais tiveram maior proximidade com os valores mínimos. Em todos os meses verifica-se que a mediana ficou muito próxima da média. A medida do grau de dispersão dos valores em relação ao seu valor médio mostra que, em média, nos meses cuja quantidade de dias de chuva é maior, o desvio padrão foi menor que nos meses com menores valores. O maior desvio padrão foi obtido no mês de janeiro $(2,1)$, considerado úmido; e o menor desvio padrão $(0,6)$ foi obtido no mês de agosto, tido como um mês seco. 


\begin{tabular}{lccccccccccccc}
\hline Estatística & Jan & Fev & Mar & Abr & Mai & Jun & Jul & Ago & Set & Out & Nov & Dez & Anual \\
\hline \hline Máximo & 22,1 & 18,1 & 18,3 & 14,5 & 6,3 & 3,6 & 2,0 & 5,4 & 9,4 & 12,7 & 15,3 & 19,2 & 121,3 \\
Média & 17,1 & 15,2 & 15,3 & 9,4 & 3,9 & 1,3 & 0,7 & 1,7 & 4,9 & 9,4 & 12,0 & 15,8 & 106,8 \\
Mediana & 16,9 & 15,1 & 16,0 & 9,0 & 3,7 & 1,2 & 0,6 & 1,4 & 4,9 & 9,3 & 11,7 & 16,0 & 108,0 \\
Mínimo & 11,0 & 12,2 & 10,1 & 6,2 & 1,5 & 0,2 & 0,1 & 0,0 & 1,9 & 7,9 & 9,3 & 12,7 & 89,4 \\
Desvio & 2,1 & 1,6 & 2,1 & 2,3 & 1,1 & 0,9 & 0,6 & 1,3 & 1,6 & 1,4 & 1,7 & 1,8 & 7,7 \\
Padrão & & & & & & & & & & & & & \\
\hline
\end{tabular}

Tabela 1: Análise estatística do Número de Dias de Chuva do estado de Mato Grosso.

\section{Conclusão}

Os meses de janeiro, abril, julho, agosto, setembro e novembro apresentaram decréscimo ou acréscimo da precipitação conforme a intensidade das variações de TSM do Oceano Atlântico em estudo, mas nada muito significativo. Dessa forma, pode-se constatar que nos demais meses do período entre 1982 e 2006 as variações TSM pouco interferiram nos dias de chuva para o estado de Mato Grosso.

Quando alguma influência dos fenômenos foi constatada, observou-se que as variações TSM positivas estão mais associadas ao NDC abaixo da média, enquanto as variações TSM negativas estão associadas ao NDC acima da média.

Outro fator culminante para atestar que as variações TSM do Atlântico Sul pouco causam efeitos evidentes nas precipitações do estado de Mato Grosso, é o fato de que nos meses de maiores intensidades desses fenômenos as curvas de tendência mantiveram-se praticamente estáveis, ou seja, não houve tendência de acréscimo ou decréscimo da precipitação dentro do período em estudo.

\section{Agradecimentos}

Os autores agradecem à Companhia de Pesquisa de Recursos Minerais/ Serviço Geológico do Brasil (CPRM/SGB), empresa pública de pesquisa do Ministério de Minas e Energia, pelo fomento que viabilizou o desenvolvimento deste trabalho.

\section{Bibliografia}

BARNSTON, A. G.; SMITH, T. M. (1996) Specification and prediction of global surface temperature and precipitation from global SST using CCA. Journal of Climate, v. 9. pp. 2660-2697. Disponível em: <http://journals.ametsoc.org/doi/abs/10.1175/15200442\%281996\%29009\%3C2660:SAPOGS\%3E2.0.CO\%3B2>. Acessado em: 11 ago. 2015.

EMPRESA BRASILEIRA DE PESQUISA AGROPECUÁRIA. Brasil em Relevo. Disponível em: <http://www.relevobr.cnpm.embrapa.br/download/index.htm>. Acessado em: fev. 2012. 
FISCHER, G. R.; DINIZ, G. B.; MARQUES, J. R. Q. (2008) Previsão do número de dias de chuva para a metade sul do Rio Grande do Sul utilizando a Temperatura da Superfície do Mar (TSM). Revista Brasileira de Meteorologia, vol. 23, n 2. pp. 146-151. ISSN 0102-7786. Disponível em: $<$ http://www.rbmet.org.br/port/revista/revista_artigo.php?id_artigo=872>. Acessado em: jun. 2012.

INSTITUTO BRASILEIRO DE GEOGRAFIA E ESTATÍSTICA. Censo 2010. Disponível em: <http://www.ibge.gov.br/cidadesat/link.php?uf=to>. Acessado em: jun. 2012.

LIEBMANN, B.; MARENGO, J.A. (2001) Interannual variability of the rainy season and rainfall in the Brazilian Amazon Basin. J Clim, 14. pp. 4308-4318.

MARCUZZO, F. F. N.; CARDOSO, M. R. D. (2015) Mapeamento espacial da precipitação pluviométrica trimestral e anual da parte Sul-Mato-Grossense da subbacia 63. In: Simpósio Brasileiro de Sensoriamento Remoto (SBSR), 17, 2015, João Pessoa. Anais... São José dos Campos: INPE. pp. 43-50. DVD, Internet. Disponível em: <http://www.dsr.inpe.br/sbsr2015/files/p0012.pdf>. Acessado em: 10 ago. 2015.

MARCUZZO, F. F. N.; CARDOSO, M. R. D.; FARIA, T. G. (2011a) Chuvas na Amazônia Mato-Grossense: Análise Histórica e Tendência Futura. Caminhos de Geografia (UFU), v. 12. pp. 65-75. Disponível em: <http://www.seer.ufu.br/index.php/caminhosdegeografia/article/view/16443>.

Acessado em: jun. 2012.

MARCUZZO, F. F. N.; MELO, D. C. de R.; ROCHA, H. M. (2011b) Distribuição Espaço-Temporal e Sazonalidade das Chuvas no Estado do Mato Grosso. Revista Brasileira de Recursos Hídricos, v. 16, p. 157-168. Disponível em: <http://www.abrh.org.br/novo/rev_rbrh.php?id=65>. Acessado em: jun. 2012.

MARCUZZO, F. F. N.; MELO, D. C. de R.; ROCHA, H. M. (2011c) Mapeamento da precipitação pluviométrica no bioma Cerrado do Estado do Mato Grosso. Boletim Goiano de Geografia (Impresso), v. 31. pp. 83-97. Disponível em: <http://www.revistas.ufg.br/index.php/bgg/article/view/16847/10257>. Acesso em: 06/2012.

MARCUZZO, F. F. N.; OLIVEIRA, N. L. (2012) Impacto do El Niño e La Niña na precipitação máxima diária do estado do Mato Grosso do Sul. Acta Geografica, v. 6. pp. 193-206. Disponível em: <http://revista.ufrr.br/index.php/actageo/article/view/630/913>. Acessado em: ago. 2015.

MARCUZZO, F. F. N.; OLIVEIRA, N. L.; CARDOSO, M. R. D. (2013) Tendência do número de dias de chuva no estado do Mato Grosso. Ciência e Natura, v. 34. pp. 59-82. Disponível em: <http://cascavel.ufsm.br/revistas/ojs2.2.2/index.php/cienciaenatura/article/view/9342>. Acessado em: ago. 2015.

MARCUZZO, F. F. N.; OLIVEIRA, N. L.; CARDOSO, M. R. D. (2012) Tendência do número de dias de chuva no estado do Mato Grosso do Sul e sua relação com o fenômeno ENOS. Revista Brasileira de Geografia Física, v. 05. pp. 1133-1144. Disponível

em: 
<http://www.revista.ufpe.br/rbgfe/index.php/revista/article/view/360/343>.

Acessado em: ago. 2015.

MARCUZZO, F. F. N; OLIVEIRA, N. L.; PINTO FILHO, R. de F.; FARIA, T. G. (2012) Chuvas na região Centro-Oeste e no Estado do Tocantins: análise histórica e tendência futura. Boletim de Geografia (UEM), v. 30. pp. 19-30. Disponível em: <http://www.periodicos.uem.br/ojs/index.php/BolGeogr/article/view/13418>.

Acessado em: ago. 2015.

MARQUES, J. R. (2005) Variabilidade espacial e temporal de precipitação pluvial no Rio Grande do Sul e sua relação com indicadores oceânicos. $210 \mathrm{f}$. Tese (Doutorado em Agrometeorologia) - Programa de Pós-Graduação em Fitotecnia, Faculdade de Agronomia, Universidade Federal do Rio Grande do Sul. Porto Alegre.

MELlO, L. T. A.; MARCUZZO, F. F. N.; COSTA, H. C.; MELO, D. C. R.; CARDOSO, M. R. D. (2011) Estudo da sazonalidade e distribuição espaço-temporal das chuvas no bioma da Mata Atlântica do estado do Mato Grosso do Sul. In: Simpósio Brasileiro de Sensoriamento Remoto (SBSR), 15, 2011, Curitiba. Anais... São José dos Campos: INPE. pp. 4452-4459. DVD, Internet. ISBN 978-85-1700056-0 (Internet), 978-85-17-00057-7 (DVD). Disponível em: <http://urlib.net/3ERPFQRTRW/3A63GMB>. Acessado em: 15 ago. 2012.

NAGHETTINI, M.; PINTO, E. J. A. (2007) Hidrologia Estatística. Belo Horizonte: CPRM.

NOAA - NATIONAL WEATHER SERVICE. (2011) Monthly Atmospheric \& SST Indices. Disponível em <http://www.cpc.ncep.noaa.gov/data/indices/>. Acessado fev. 2012.

OLIVEIRA, N. L.; MARCUZZO, F. F. N. (2013) Correlação da variação da temperatura na parte sul do Oceano Atlântico com o número de dias de precipitação pluviométrica do Estado do Mato Grosso do Sul. Geoambiente On-line, v. 20. pp. 61-82.

Disponível em: <http://revistas.jatai.ufg.br/index.php/geoambiente/article/view/26087/15035>. Acessado em: ago. 2015.

PEEL, M. C.; FINLAYSON, B. L.; MCMAHON, T. A. (2007) Updated world map of the Köppen-Geiger climate classification, Hydrol. Earth Syst. Sci, 11. pp. 16331644.

PINTO, E. J. de A.; AZAMBUJA, A. M. S. de; FARIAS, J. A. M.; SALGUEIRO, J. P. de B.; PICKBRENNER, K. (Coord.). (2011) Atlas pluviométrico do Brasil: isoietas mensais, isoietas trimestrais, isoietas anuais, meses mais secos, meses mais chuvosos, trimestres mais secos, trimestres mais chuvosos. Brasília: CPRM; Programa Geologia do Brasil; Levantamento da Geodiversidade; Sistema de Informação Geográfica-SIG - versão 2.0 - 1 DVD, Escala 1:5.000.000, atualizado em novembro/2011. Equipe Executora: Adriana Burin Weschenfelder; André Luis M. Real dos Santos; Andressa Macêdo Silva de Azambuja; Carlos Eduardo de Oliveira Dantas; Denise Christina de Rezende Melo; Érica Cristina Machado; Francisco F. N. Marcuzzo; Jean Ricardo da Silva do Nascimento; José Alexandre Moreira Farias; Margarida Regueira da Costa; Paulo de Tarso R. Rodrigues; 
Vanesca Sartorelli Medeiros. Disponível em: <http://www.cprm.gov.br/publique/cgi/cgilua.exe/sys/start.htm?infoid=1351\&sid=9 >. Acessado em: 03 abr. 2013.

SILVA, A. P. N.; MOURA, G. B. A.; GIONGO, P. R.; MEDEIROS, S. R. R. (2011) Correlação entre as Temperaturas da Superfície do Mar e a quantidade da precipitação na estação chuvosa no Nordeste do Estado de Pernambuco. Revista Brasileira de Meteorologia, vol. 26, $\mathrm{n}^{\circ}$ 1. pp. 149-156. ISSN 0102-7786. Disponível em: <http://www.rbmet.org.br/port/revista/revista_artigo.php?id_artigo=1024 >. Acessado em: jun. 2012

SOUSA, J. R. A.; ALMEIDA, R. M. B.; ROLIM, P. A. M. (2008) Influência do Dipolo do Atlântico nas Precipitações do Leste da Amazônia/Litoral Norte Brasileiro. CBMET - CONGRESSO BRASILEIRO DE METEOROLOGIA, XV. Anais: XV Congresso Brasileiro de Meteorologia. São Paulo. Disponível em: < http://www.cbmet.com/busca.php >. Acessado em: jun. 2012

WALKER, G. T. (1928) Ceará (Brazil) famines and the general air movement. Beitrage zur Physik der freien Atmosphare, v.14. pp. 88-93. 